\title{
Chapter 15: EMERGING TRENDS IN LEGISLATION IN EUROPE
}

\section{Helen Xanthaki, Professor of Law, UCL; Director, International PG Laws Programme, UoLondon}

\begin{abstract}
This chapters attempts to use the wisdom offered by authors in previous chapters in order to define legislative quality in the EU. And to express the dreamy future of further initiatives in the field. 'Blue sky' choices or future reality, only time will tell. But the book ends with a look at the future, in hope of more work and more success in legislation for academics and practitioners.
\end{abstract}

\subsection{The EU's regulatory framework for legislative quality ${ }^{1}$}

The EU's long engagement with legislative quality is characterised by a strong political driving force behind the regulatory agenda by a number of member states. ${ }^{2}$ Although this could have led to a common law prevalence in drafting conventions, the emerging legislative style is a unique EU one. It balances admirably common and civil law structures, thus accommodating both families of law. But at the same time it respects the legal intricacies of EU law, such as the prevalence of consistent EU case-law as a source of binding legal norms.

The framework within which this dynamic process takes place is via a long list of documents, mainly of non-binding nature, that set rules for the process and format of legislative drafting applicable to all EU institutions.

The first set of concrete quality promoting rules is expressed in the 1992 Sutherland Report. Lord Sutherland sets five criteria that each new legislative measure must meet as a means of achieving legislative quality. These are: the need for regulatory action; the choice of the most effective course of action, be it legislative or alternative; proportionality of the measure to the desired regulatory results; consistency of the proposed measure with existing measures; and wide consultation at the preparatory stage.

\footnotetext{
${ }^{1} \mathrm{H}$ Xanthaki 'The Problem of Quality in EU legislation: what on earth is really wrong?' [2001] 38 Common Market Law Review 651.

${ }^{2}$ For example the UK initiatives below, the Dutch contribution with the Koopmans Report; the Scheveningen Conference, and the Amsterdam IGC etc.
} 
But how could one put the Sutherland Report into effect, with specific reference to drafting conventions and rules? Two months after Lord Sutherland's report, in December 1992, the European Council demanded clearer and simpler legislation. ${ }^{3}$ In June 1993 the Council clarified these concepts, and introduced concrete measures for their attainment by use of a Resolution on legislative quality: the Resolution touched upon wording, structure, and consistency with the content of existing legislation. ${ }^{4}$ In an attempt to make legislation more accessible, the Resolution called for clear, simple, concise, and unambiguous wording. Practices encouraged by the Resolution were: the use of the same term throughout the act, the use of the accepted structure of chapters - sections - articles - paragraphs, compliance with the role of the preamble as a means of justification of the enacting provisions in simple terms, clear determination of the rights and obligations deriving from the act, clear reference to the act's date of entry into force, and consistency of the provisions of various acts. Practices discouraged by the Resolution were: the use of unnecessary abbreviations, Community jargon, long sentences, imprecise references to other texts, too many cross-references, political statements without legislative character, pointless repetitions of existing provisions, and inconsistencies with existing legislation. With specific reference to acts amending earlier legislative texts, the Resolution discouraged the inclusion of autonomous provisions, which could not be directly incorporated into the existing act. The Resolution is very similar to a legislative manual in the national context, but it is much shorter, and includes an imbalanced range of concrete conventions and general principles for drafters. Although the Resolution cannot be attributed with originality or innovation in the prescribed drafting rules and conventions, its great value lies in its unprecedented, for the EU, focus on legislative quality, accessibility of legislation, and the concept of set, clear criteria for the evaluation of EU legislative texts. ${ }^{5}$ But a Resolution carries little binding force, and therefore limited legal value; and in any case this Resolution was of a general prescriptive character.

And so the onus was for the various actors of the legislative process to introduce concrete measures putting the Sutherland Report and the Resolution into effect in specific areas of law-making. Thus, in December 1994 the Council, the Commission and the

\footnotetext{
${ }^{3}$ See Edinburgh European Council, "Conclusions of the Presidency", Bulletin EC 12/92, 7.

${ }^{4}$ See Council Resolution of 8 June 1993 on the quality of drafting of Community legislation, OJ C 166/1, 17 June 1993, 1.

5 These rules are also included in the Council Decision 93/662/EC of 6 December 1993 adopting the Council's Rules of Procedure, OJ L 304/1, 10 December 1993.
} 
Parliament set out to detail the guidelines of the Resolution in a concrete, albeit still not binding, Inter-institutional Agreement on the official codification of legislative texts. The Resolution and Agreement are of course directly linked: the Resolution declares that 'the general objective of making Community legislation more accessible should be pursued not only by making systematic use of EU consolidation but also by implementing the following guidelines'. ${ }^{6}$ In June 1995 the Molitor Group applied the Sutherland Report criteria to legislative and administrative simplification. ${ }^{7}$ This was supplemented in 2003 by the notion of prioritisation for the purposes of simplification. ${ }^{8}$

And whilst this was going on the Commission took it upon itself to provide a more principled, but still not binding, stance on law-making. In 1995 and 1996 the Better Lawmaking Reports ${ }^{9}$ identified the regulatory aims of the EU's legislative policy: legislative quality, consistency, openness in the drafting process, carefully planned and co-ordinated legislative process, and thorough monitoring and evaluation of the legislation. In parallel to a focus on legislative quality at the EU level the Commission identified the crucial role of legislative quality in the national implementing measures as a factor of quality of EU regulation. This is evident in the Commission's 1996 SLIM initiative (Simpler Legislation for the Internal Market), which, with the strong encouragement of Internal Market Ministers, targets simplification of both EU and national implementing legislation. ${ }^{10}$ The theme was confirmed in June 1997 where the Commission's approach to simplification extended expressly to national measures also. ${ }^{11}$ And also in the Commission's 1997 Better Law-making Report, which called upon the drafting

\footnotetext{
${ }^{6}$ See Interinstitutional Agreement of 20 December 1994, 'Accelerated working method for official codification of legislative texts', OJ C 293/2, 8 November 1995, OJ C 102/2, 4 April 1996.

${ }^{7}$ See Report of the Group of Independent Experts on legislative and administrative simplification: Summary and Proposals, COM (95) 288 final, 21 June 1995; also see Commission's comments on the report SEC (95) 2121 final of 29 November 1995; and the European Parliament Resolution of 4 July 1996, OJ C211, 22 July 1996, 23.

${ }^{8}$ See Communication from the Commission to the Council, the European Parliament, the European Economic and Social Committee and the Committee of the Regions, 'Updating and simplifying the Community acquis', SEC (2003) 165, COM/2003/0071 final.

${ }^{9}$ See Better Lawmaking 1995: report of the Commission to the European Council [of Madrid] on the application of the principles of subsidiarity and proportionality, on simplification and codification, CSE(95)580, Bulletin, 11-1995, point 1.9.2; also see Better Lawmaking 1996: report of the Commission to the European Council [of Dublin] on the application of the principles of subsidiarity and proportionality, on simplification and consolidation, CSE (96)7.

${ }^{10}$ See Communication from the Commission to the Council and the European Parliament, 'Simpler legislation for the internal market (SLIM): a pilot project', COM(96)204 fin.; also see Resolution of the EP of 10 April 1997 on the communication from the Commission to the Council and the EP 'Simpler legislation for the internal market (SLIM): a pilot project', $\mathrm{COM}(96) 204$ fin. (A4-0108/97, OJ no C 132/213, 28 April 1997).

${ }^{11}$ See COM(97)618 final, 2.
} 
authorities of the member states 'to work towards the effective implementation of Community law and play an active part in the process of improving the quality of legislation'. ${ }^{12}$ And again in the Informal Meeting of Internal Ministers of 13-14 February 1998, Ministers unanimously stressed their strong support for legislative simplification of national and Community rules. The rationale of this policy was expressed clearly in the 1998 Better Law-making Report 1998: A Shared Responsibility ${ }^{13}$, which pronounced member states as '...the main producers of legislation and hence the most direct cause of the burden [on firms].' In a series of documents the Commission extended its emphasis on the quality of legislative measures by the member states to the need for monitoring and evaluation of transposition of EU instruments both pre and post accession. ${ }^{14}$

But what exactly are the elements of legislative quality, which the Commission so eloquently extended both to the EU and the member states? The 1998 Commission Staff Working Paper entitled Making Single Market Rules More Effective, Quality in Implementation and Enforcement ${ }^{15}$ clarifies the necessity for, purpose and content of quality in legislation: clear and simple legislation helps businesses and citizens to comply with the law without excessive burdens; it facilitates its enforcement; and it addresses complaints for excessive wrong tape often leading to cases for damages, such as Francovich. All this can be achieved by use of legislation that is easy to transpose and apply and takes into account the views of interested parties expressed in consultation under the 1998 Regulatory Policy Guidelines of the Commission and the 2002 General principles and minimum standards for consultation of interested parties by the Commission. Accountability, effectiveness and proportionality were put forward as the main elements of better law-making in the 2002 Communication on European Governance: Better law-making. ${ }^{16}$ Moreover, the Commission Communication to the European Council 'Legislate Less to Act Better: the Facts' emphasised the need to concentrate on policy priorities with strict application of the subsidiarity and

\footnotetext{
${ }^{12}$ See Bulletin EU 11-1997, point 1.1.1.

${ }^{13}$ See COM(1998)715 final.

${ }^{14}$ See Annual report 2007 on monitoring the application of Community law COM(2008)777 (18

November 2008); A Europe of results - applying Community law COM(2007)502 (5 September 2007);

Annual report 2006 on monitoring the application of Community law; COM(2007)398 (17 July 2007) and Annex SEC(2007)976; Annual report 2005 on monitoring the application of Community law $\operatorname{COM}(2006) 416$ (24 July 2006); Better monitoring the application of Community law Commission communication - COM(2002)725 (2002).

15 See SEC(1998) 903, 25 May 1998, 3-5.

${ }^{16}$ See Communication from the Commission - European Governance: Better lawmaking, COM/2002/0275 final.
} 
proportionality principles (legislate less), the need for improved consultation procedures, and the need for clearer, simpler, and more accessible legislation (act better). These aims are achievable through the reduction of legislative proposals; the use of alternatives to legislation as a regulatory tool; the quality of legislative drafting through the introduction of drafting guidelines for clear, coherent and unambiguous legislation; the simplification of legislation through SLIM; the appropriate use of formal consolidation [or codification, in today's terminology], recasting, and informal consolidation; easier access to information; proper transposition; shared responsibility amongst institutions; and rationalising of national legislation.

The culmination of rules for legislative quality came with the 1998 Interinstitutional Agreement on common guidelines for the quality of drafting of Community legislation: ${ }^{17}$ Community acts must be clear, simple, precise, concise, and with homogeneous content. Drafting must be appropriate to the type of act concerned, and to the audience to whom it is addressed. Terminology must be internally and externally consistent. The standard structure of title - preamble - enacting terms - annexes if necessary) applies. The title offers a full indication of the subject matter. Citations set out the legal basis of the act. Recitals set out concise reasons for the chief provisions of the enacting terms without paraphrasing or reproducing them. Only clauses of normative nature can be included in legislation. Internal and external references must be kept to a minimum. Repeals must be introduced expressly. Dates of transposition or enforcement must be introduced clearly as day/month/year. This was supplemented by the 2003 Interinstitutional Agreement on Better Law-Making. But the 2003 Agreement focuses only on: improving inter-institutional coordination and transparency; providing a framework for alternative regulatory instruments; increasing the use of impact assessments; and simplification of EU law ${ }^{18}$.

But the 1998 Agreement remains non-binding and rather fragmented in its approach to legislative quality. It seems that on its own, and even in combination with the many relevant EU texts referred to here, the Agreement and therefore the EU have failed to demonstrate what the elements of legislative quality must be.

\footnotetext{
${ }^{17}$ See OJ C 73, 17 March 1999, 1.

${ }^{18}$ See Parliament, Council and Commission Inter-institutional Agreement on better law-making, $O J$ 2003/C 321/01.
} 


\subsection{The post-Lisbon Smart Regulation initiative}

The fury of action for the achievement of legislative quality in the EU ends somewhere in 2003. Numerous policy documents continued to refer to Better Regulation, which continued to be at the forefront of the EU's governance debate, but a closer look at them shows beyond doubt a transfer from legislation as an autonomous product to legislation as a regulatory tool. This is of course exceptionally insightful as legislation is indeed a tool for regulation. But, unfortunately, in the EU this conceptual move led to a notable ignorance of legislation altogether at least from a drafting perspective. One could source the conceptual framework behind this movement as far back as 2001 and the Mandelkern Group Report on Better Regulation. It is notable that since 2001 the Better Regulation Reports are pursuant to and therefore limited to proportionality and subsidiarity, whereas from 2007 even the title of Better Regulation reports has been usurped by subsidiarity and proportionality, thus excluding scope for legislative quality conventions and innovative assessments. The 2008 Second strategic review of Better Regulation in the EU focuses solely on administrative burdens, legislative scrutiny, reducing the number of legislative instruments, and emphasising the shared responsibility of the EU and member states. Similarly, the 2009 Third strategic review of Better Regulation in the EU is another prime example of this move from legislation to regulatory agendas: although clear, precise, and accessible legislation lies at the ether of regulatory reform, none of the recommendations address it: pre and post legislative scrutiny are the only focus.

The most recent innovation in the field comes with the Smart Regulation Agenda. ${ }^{19}$ The October 2010 Commission Communication on Smart Regulation constitutes the formal passing from the old Better Regulation Agenda to the new Smart Regulation Agenda. ${ }^{20}$ The Commission identified three key messages in the Agenda. First, Smart Regulation is about the whole policy cycle, and thus touches upon the design of a piece of legislation, its implementation, enforcement, evaluation, and revision. Second, Smart Regulation remains a shared responsibility between the EU institutions and the Member States. Third, the views of users of regulation have a key role to play in

\footnotetext{
${ }^{19}$ See H Xanthaki 'The regulatory reform agenda and modern innovations in drafting style' in L Mader (ed.) Regulatory Reform (Baden-Baden, Nomos, 2013), 128.

${ }^{20}$ See European Commission 'Smart Regulation in the European Union' Commission communication, COM(2010)543, 8 October 2010, http://eurlex.europa.eu/LexUriServ/LexUriServ.do?uri=CELEX:52010DC0543:EN:NOT.
} 
Smart Regulation, as consultation is an element of democracy. In other words, the novelty of Smart Regulation refers to three main themes: smart regulation throughout the policy cycle; shared responsibility; and stakeholder engagement. ${ }^{21}$

There is no doubt that Smart Regulation is revolutionary. The reaction of the experts to the Commission's agenda has been positive, although already need for further action has been identified. This includes the need to carry out impact assessments for every new regulatory proposal; to improve the informative value of roadmaps; to make the Commission's Impact Assessment Board more independent; to conduct systematic ex post-evaluations from the end users' perspective; to strengthen the role of the High Level Group; and to consult the public. ${ }^{22}$ Smart Regulation presents obvious positive points. It follows Stefanou's identification of the drafting process as a part of the legislative process, which is a part of the policy process ${ }^{23}$. It confirms that EU regulation is a shared responsibility of the institutions and member states. And it affirms the need for in depth consultation. Focus is placed on the simplification of EU law via the reduction of administrative burdens past the expected $25 \%$ cuts in red tape by 2012 ; evaluation of law effectiveness and efficiency ex ante via fitness checks on key areas (environment etc.), and via strategic general policy evaluations; selection of the 'the best possible' legislation through Impact Assessment, improvement of implementation record, via post legislative scrutiny, SOLVIT, and EU Pilot; and achieving clearer and accessible legislation via simple language, codification, recasting, and e-access. These are worthy aims. And the Commission can show considerable success. For example the EU's Impact Assessment system has been praised as first class. ${ }^{24}$ The question is how these noble aims are going to be achieved.

\footnotetext{
${ }^{21}$ See H McColm 'Smart Regulation: The European Commission's Updated Strategy' [2011] European Journal of Risk Regulation 9, 9.

${ }^{22}$ See 'Common Position Paper of the five European independent advisory boards for cutting red tape and better regulation', Adviescollege toetsing regeldruk (ACTAL), The Netherlands; Nationaler Normenkontrollrat (NKR), Germany; Regelrådet, Sweden; Regulatory Impact Assessment Board (RIAB), Czech Republic; Regulatory Policy Committee (RPC), United Kingdom, http://www.regelradet.se/wpcontent/uploads/2012/09/2012-Reaction-on-consultation-Smart-Regulation.pdf

${ }^{23}$ See C Stefanou 'Drafters, drafting and the policy process' in C Stefanou and H Xanthaki Drafting Legislation: A Modern Approach (Aldershot, Ashgate, 2008) 321.

${ }^{24}$ See OECD 2011 'Sustainability in Impact Assessments - A review of Impact Assessment Systems in selected OECD Countries and the European Commission', European Parliament 2011, 'Comparative study on the purpose, scope and procedures of impact assessments carried out in the Member States of the EU', CEPS/University of Exeter 2012, 'Regulatory Quality in the European Commission and the UK: Old questions and new findings'.
} 
Simplification of EU law is indeed a wonderful goal. A depressing [or it is impressive?] $74 \%$ of Europeans believe that the EU generates too much red tape. ${ }^{25}$ And the Commission has responded to it via impact assessments and stakeholder consultation, and via regular fitness checks undertaken within the Regulatory Fitness and Performance Programme (REFIT) of December 2012. These initiatives have contributed to a reduction of red tape by well above the $25 \%$ target set out in the Administrative Burden Reduction programme: ${ }^{26}$ the precise figures correspond to a decrease of $25 \%$ of burden in 13 priority areas equivalent to savings of EUR 30.8 billion with a further EUR 5 billion still pending adoption by the co-legislator.

But simplification cannot be taken to mean simply a streamlining of legislation and a reduction of administrative burdens. In fact, the Smart Regulation agenda neglects to address a number of crucial aspects of simplification without which reduction of administrative burdens cannot be achieved. What about simplicity of the chosen policies? If a policy choice is complex in itself, then the reduction of red tape will not suffice to make it accessible to the citizens. What about simplicity in the selected regulatory means? Is the notoriously user unfriendly legislation not a most complex regulatory tool? And so reducing administrative burdens via legislation carries inherent complexity, which may well endanger the end result. What about the chosen drafting style as a means of simplifying the expression of a simply policy when a simpler regulatory tool is considered ineffective? A complex legislative style would diminish the actual effect of any simplification effort irrespective of what the percentage of administrative burdens in the simple policy chosen may be: if the users cannot understand the language of the law, how can they benefit from the opportunities created by a policy of reduced red tape? What about straightforward enforcement methods? And could one rely on a reduction of administrative burdens within the EU text, if the national implementing measures are complex and seize on any opportunity for discretion in the EU text in order to add further burdens? And finally could EU law be considered simple when the methods of pre- and post-legislative scrutiny utilised are inherently complex and therefore inaccessible for the users?

\footnotetext{
${ }^{25}$ See Eurobarometer Question QA16.4 on page 59: http://ec.europa.eu/public_opinion/archives/eb/eb79/eb79_anx_en.pdf.

${ }^{26}$ See SWD(2013)401 final.
} 
Similarly, evaluation of law effectiveness and efficiency ex ante is a fantastic initiative in theory. It is defined as a judgment of interventions according to their results and impacts, and the needs they aim to satisfy. ${ }^{27}$ But can it be achieved simply via fitness checks and general policy evaluations? In a legislative environment where the definition of effectiveness has not been provided conclusively, the goal that the regulatory team is supposed to be trying to achieve becomes a moving target, a vague and ambiguous goalpost, which carries a different meaning for the different actors in the regulatory process, much more so between EU and national levels. But even where the concept of effectiveness appears clear, which are the specific criteria of effectiveness by way of successful regulation that must be used in reference to a specific piece of legislation? The application of the generic elements of the semantic field of the concept of effectiveness in the specific context of a piece of legislation as applied in the specific legal system that serves a specific society in a specific time is not an easy task, and should not really be ignored or left to chance. There is a dire need to ensure that the criteria for effectiveness of any piece of legislation are agreed between policy makers, law experts, and legislative drafters, and that they are clearly expressed in the legislation itself via perhaps their inclusion in a purpose clause or an objectives article. These can then be carried through to post legislative scrutiny. And then utilised to confirm effectiveness, thus allowing the text to continue its legislative life.

But how will ineffectiveness be addressed? What if the effectiveness criteria are not met by the piece of legislation at the pre-set time of post legislative monitoring: will the legislation die an automatic death via perhaps a sunset clause, will it continue to plague the statute book as it stands until an enlightened decision maker decides to address the problem, or will it lead to an automatic exercise of fine-tuning via perhaps an amending piece of legislation?

Moreover, Smart Regulation fails to identify the way in which, if at all, evaluation will take place at the member state level. Here other considerations should also come into play. Will national scrutiny be compulsory or could the member states be offered discretion on the basis of national sovereignty in the legislative making process? Moreover, Smart Regulation fails to address the extent of any national scrutiny process, namely whether it must relate strictly to the national implementing measures or whether

\footnotetext{
${ }^{27}$ See G Luchetta 'Impact Assessment and the Policy Cycle in the EU' [2012] European Journal of Risk Regulation 561, 572-573.
} 
it can refer to the original EU text. This is rather crucial, especially in reference to national legislation, which departs from the policy and law of the EU by means of either a direct or indirect breach or even legitimately by means of an acceptable exercise of discretion as would be the case with the implementation of a Directive. And what if the national scrutiny exercise identifies a flaw in the EU policy? Can that be reported back to the EU and will this result in any action at the EU level?

Moreover, the initiative fails to define efficiency. It is unclear whether that refers to a mathematical exercise involving financial cost or whether social and other impact must be calculated towards the reduction of burdens, or indeed how these can be calculated.

The improvement of the implementation record is a third worthy point of reference for Smart Regulation. But once again one has to distinguish between the aim and the proposed methods for its achievement. Can implementation be improved solely via post legislative scrutiny, availability of SOLVIT, and the EU Pilot on clarification and assistance with the application of EU legislation? What about clear guidance on the definition of complete transposition for new, older and aspiring member states? What about clear guidance on the definition of quality in legislation for the purposes of EU drafting but also EU transposition? What about the establishment of national drafting offices with trained specialist drafters vetting (if not drafting) implementation measures on the basis of the UK model for drafting national primary legislation [Office of Parliamentary Counsel]? What about extending the scrutiny of implementation beyond substantive transposition to technical quality of transposition?

And finally, who would disagree with the election of the 'the best possible' legislation? But is this really achievable simply via Impact Assessments, clearer and accessible legislation, simple language, codification, recasting, and e-access? What about opening the debate for a holistic approach to effectiveness in the sense of the use of legislation as a tool for regulation? What about setting a hierarchy of goals for the drafter? What about training drafters to achieve these goals? What about considering a central drafting office with trained drafters within EU institutions, including the Commission, 
the Council, and the Parliament? What about training national drafters to contribute to the effort? ${ }^{28}$

And so even post Lisbon EU legislative quality continues to face challenges which have remained unaddressed, for the most part. The analysis of the relevant EU initiatives, namely the Better Regulation agenda, identified a pause somewhere around 2003. Despite the fury of activity in the field of legislative quality until then, all initiatives from the EU after that date refer to legislative quality as an aim but have transferred the focus of attention to holistic regulatory quality thus leaving legislative quality aside. ${ }^{29}$

The move to regulatory quality as the main focus of the EU's better governance campaign is by no means a negative development in the field. Indeed, legislative quality is an intrinsic part of regulatory quality: without regulatory quality one cannot perceive the notion of legislative quality. As legislative drafting can only aspire to effectiveness, namely to the production of a legislative text that, with the cooperation and synergy of all other actors in the policy process, can achieve the regulatory aims, one cannot possibly expect it possible to produce quality legislation when the regulatory aims are erroneous or illegal, when the choice of legislation as a regulatory tool is inappropriate, or indeed when the implementation of the legislation has not been thought through. But at the same time one cannot possibly perceive regulatory quality without, in cases where legislation is the appropriate regulatory tool, legislative quality. To me, this is the great error of the EU's current strategy. By turning the focus of attention from legislation to regulation the EU seems to have forgotten about legislation altogether, somehow trying to simply wish away the continuing problems of legislative quality. ${ }^{30}$ The same conclusion is reached by the analysis of Smart Regulation, the 2010 EU initiative constituting the successor of Better Regulation. This conclusion is confirmed by an analysis of the new Interinstitutional agreement on Better Law-Making between the European Parliament, the Council of the European Union and the European Commission on Better Law-Making made on 13 April 2016. One again, the institutions re-affirm their common goal for effectiveness of legislation but fail to address their drafting altogether: emphasis is on procedural issues (such as planning and monitoring) and on pre and post legislative

\footnotetext{
${ }^{28}$ For a full presentation of my critique to Smart Regulation see H Xanthaki 'Implementation of EU legislation', Oral Evidence, Public Hearing at the Legal Affairs Committee of the European Parliament 'Better Regulation' Hearing, Brussels, 21 June 2011.

${ }^{29}$ See M Mousmouti 'The Effectiveness Test' [2012] Legisprudence 191, 196.

${ }^{30}$ See C-H Montin 'Smart Regulation in the European Union', http://montin.com/documents/smartregulation.pdf, (29.11.2012).
} 
scrutiny. But the actual drafting is ignored, and therefore the criteria by which legislation as a product is to be assessed remain vague and therefore inapplicable in practice. ${ }^{31}$

What is even more disappointing is the 2020 Agenda for Europe, where not only Better Regulation but also Smart Regulation is ignored. The question is why the EU felt that they could move from Better Regulation to Smart Regulation, and then to a strategy for growth and competitiveness. From the perspective of legislative studies at least, none of the two moves make sense. Why would the EU decide to leave Better Regulation and Smart Regulation aside, when neither of these agendas has born the desired fruits? Surely, one could not seriously support the argument that EU legislation and national implementing legislation, or indeed the EU regulatory environment has reached perfection? One is tempted to attribute this move to an underlying policy of competitiveness for businesses rather than a policy for better legislation in Europe. Perhaps the legislative and then regulatory quality agendas are viewed by the EU solely as a means of pursuing the policy aim of growth and competitiveness. It is precisely this aim which is repeated, and even more clearly expressed, in the 2020 Agenda for Europe.

In view of this, where is Europe going with reference to legislative quality and quantity? What the EU has clumsily missed here is a unique opportunity to finally balance its focus of attention to both businesses and citizens. While the first enjoy the fruits of Better Regulation, Smart Regulation, and the 2020 Agenda for Europe, citizens are still facing the same issues of confusion stemming from the multitude of bad EU laws (not tackled by SLIM as they did not relate to SME), and bad regulation (not tackled by Smart Regulation since administrative burdens were not applicable). This imbalance may well be intentional. But it remains un justifiable within the focus on citizen and citizenship expressed clearly in the Treaty of Lisbon. And it cannot be accommodated within the emphasis on social equity for EU citizens so eloquently professed in the Treaty of Lisbon, which declares the passage from the Internal Market to a forum of citizenship, international justice, and peace.

It appears therefore that the new challenge for Europe in the field of EU legislative studies is to apply Better Regulation, Smart Regulation, and the 2020 Agenda for Europe to citizens, along with businesses, thus showing that the Treaty of Lisbon is not a list of

\footnotetext{
${ }^{31}$ Also see Communication from the Commission to the European Parliament, the Council, the European Economic and Social Committee and the Committee of Regions, "Better regulation for better results - An EU agenda", 19.5.2015 $\operatorname{COM(2015)~} 215$ final.
} 
good political intentions, but an accurate reflection of the new EU for its citizens and peoples. The challenge is to go back to Better Regulation and Smart Regulation, and assess their success from the point of view of the citizens using the Treaty's citizenship concept as a focus. Transferring the focus from businesses to citizens would tint the picture of the effectiveness of these three regulatory initiatives with much darker colours. Because the amount of work that remains in order to make EU legislation and EU regulation palatable is daunting. But absolutely necessary.

Does this mean that there is only gloom and doom ahead for Europe and its legislation? Far from it. The EU as a regional organisation is lagging behind whilst a number of ground breaking initiatives are pursued within the Member States. At the same time the academic discipline of legislative studies is enriching Europe with innovative concepts for better legislative quality. Let us refer to a selection of these concepts. Blue sky ideas or a realistic way forward: only time will tell.

\subsection{Legislative quality in the future: blue sky initiatives or a realistic way forward?}

The first innovation in the area of drafting within the Member States is an unprecedented agreement over what constitutes legislative quality. From a legislative studies perspective good legislation is legislation that manages to achieve the desired regulatory results. ${ }^{32}$ Since governments use legislation as a tool of successful governing ${ }^{33}$, namely as a tool for putting into effect policies that produce the desired regulatory results ${ }^{34}$, the qualitative measure of successful legislation coincides with the prevalent measure of policy success, which is the extent of production of the desired results. ${ }^{35}$ Provided that the government's choice is indeed to put a policy to effect rather than only on paper. ${ }^{36}$ Within this context, regulation is the process of putting government policies into effect to the degree and

\footnotetext{
${ }^{32}$ See H. Xanthaki, Drafting Legislation: Art and Technology of Rules for Regulation, (2014, Hart Publishers, Oxford), chapter 1.

${ }^{33}$ See OECD, 'Recommendation of the Council on Improving the Quality of Government Regulation', 9 March 1995, C(95)21/Final.

${ }^{34}$ The executive branch of government is no longer expected to confine itself to the mere making of proposals: it has to see them through. See J. Craig Peacock, Notes on Legislative Drafting (Washington, REC Foundation, 1961) 3.

${ }^{35}$ See N. Staem, 'Governance, Democracy and Evaluation' (2006) 12(7) Evaluation 7, 7.

${ }^{36}$ And the choice is the governments not the drafters: see P. Delnoy, Le rôle des légistes dans la détermination du contenu des norms, 2013 Report for the International Cooperation Group, Department of Justice, Canada, http://www.justice.gc.ca/fra/apd-abt/gci-icg/publications.html, 3.
} 
extent intended by government. ${ }^{37}$ Legislation, as one of the many regulatory tools available to government ${ }^{38}$, is the means by which the production of the desired regulatory results is pursued. And in application of Stefanou's scheme on the policy, legislative, and drafting processes ${ }^{39}$, legislative quality is a partial but crucial contribution to regulatory quality. ${ }^{40}$ This promotes the current synergetic approach to legislation eloquently expressed by Richard Heaton, former First Parliamentary Counsel and Permanent Secretary of the Cabinet Office:

'I believe that we need to establish a sense of shared accountability, within and beyond government, for the quality of what (perhaps misleadingly) we call our statute book, and to promote a shared professional pride in it. In doing so, I hope we can create confidence among users that legislation is for them.' ${ }^{41}$

This approach feeds into this diagram of elements of regulatory and legislative quality. ${ }^{42}$

\footnotetext{
${ }^{37}$ See National Audit Office, Department for Business, Innovations and Skills, 'Delivering regulatory reform', 10 February 2011, para 1.

${ }^{38}$ Tools for regulation vary from flexible forms of traditional regulation (such as performance-based and incentive approaches), to co-regulation and self-regulation schemes, incentive and market based instruments (such as tax breaks and tradable permits) and information approaches. See Better Regulation Task Force (BRTF), 'Routes to Better Regulation: A Guide to Alternatives to Classic Regulation', December 2005; also see J. Miller, James, 'The FTC and Voluntary Standards: Maximizing the Net Benefits of Self-Regulation' (1985) 4 Cato Journal 897; and OECD Report, 'Alternatives to traditional regulation', para 0.3; and also OECD, Regulatory Policies in OECD Countries: From Interventionism to Regulatory Governance (Paris, OECD, 2002).

${ }^{39}$ See C. Stefanou, 'Legislative Drafting as a form of Communication' in L. Mader and M. TravaresAlmeida (eds), Quality of Legislation Principles and Instruments (Baden-Baden, Nomos, 2011) 308; and also see C. Stefanou, 'Drafters, Drafting and the Policy Process' in C. Stefanou and H. Xanthaki (eds), Drafting Legislation: A Modern Approach (Aldershot, Ashgate, 2008) 321.

${ }^{40}$ In fact, there is an emergence of a public interest in good quality of rules: see M. De Benedetto, M. Martelli and N. Rangone, La Qualità delle Regole (Bologna, SE il Mulino, 2011), 23.

${ }^{41}$ See R. Heaton, 'Foreword' in Cabinet Office, Office of Parliamentary Counsel When Laws Become Too Complex, 16 April 2013.

${ }^{42}$ See H. Xanthaki,'On transferability of legislative solutions: the functionality test' in C. Stefanou and H. Xanthaki (eds), Drafting Legislation: A Modern Approach - in Memoriam of Sir William Dale, above, n. 12,1 .
} 


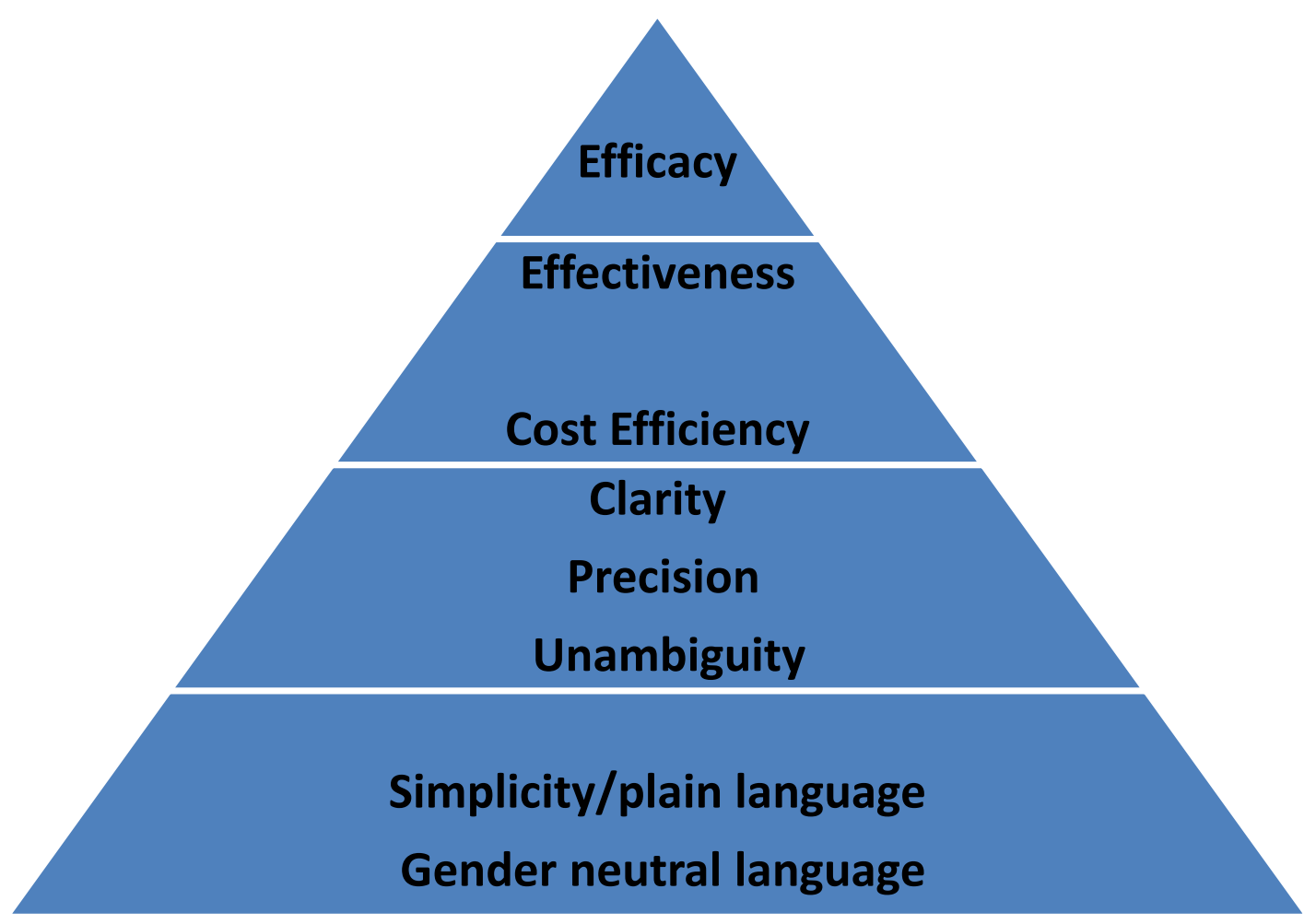

Efficacy as synonymous to regulatory quality is the extent to which regulators achieve their goal. ${ }^{43}$ Regulatory efficacy is achieved via legislative effectiveness. ${ }^{44}$ OPC repeat their aspiration to effectiveness as a contribution to or in balance with accuracy but do not define the term. ${ }^{45}$ Effectiveness is the ultimate measure of quality in legislation. ${ }^{46}$ If one subjects effectiveness of legislation to the wider semantic field of efficacy of regulation as its element, effectiveness manages to hold true even with reference to diverse legislative phenomena, such as symbol legislation, or even the role of law as a ritual. If the purpose of legislation is to serve as a symbol, then effectiveness becomes the measure of achieved inspiration of the users of the symbol legislation. If the legislation is to be used as a ritual, effectiveness takes the robe of persuasion of the users who bow down to its appropriate rituality. Effectiveness requires a legislative text that can (i) foresee the main projected outcomes and use them in the drafting and formulation

\footnotetext{
${ }^{43}$ See ibid, 126.

${ }^{44}$ See C. Timmermans, 'How Can One Improve the Quality of Community Legislation?' (1997) 34 Common Market Law Review 1229, 1236-7.

45 See Office of Parliamentary Counsel, 'Working with OPC', 6 December 2011; and OPC, 'Drafting Guidance', 16 December 2011.

${ }^{46}$ See H. Xanthaki, 'On Transferability of Legal Solutions' in C. Stefanou and H. Xanthaki (eds.) Drafting

Legislation, A Modern Approach, above, n 19, 6.
} 
process; (ii) state clearly its objectives and purpose; (iii) provide for necessary and appropriate means and enforcement measures; (iv) assess and evaluate real-life effectiveness in a consistent and timely manner. ${ }^{47}$

Leaving cost efficiency out of the equation, since it is an economic-political rather than purely legal choice ${ }^{48}$, effectiveness is promoted by clarity, precision, and unambiguity. In turn, clarity, precision, and unambiguity are promoted by plain language and gender neutral language.

Plain language has been promoted as the main tool for achieving clarity and in turn effectiveness of legislation. But its meaning has been transformed. Plain language is defined by Peter Butt as clear and effective for its audience. ${ }^{49}$ In its traditional definition plain language is a general and inevitably vague pursuit for techniques that can produce a text that may be understood by the users in the first reading. This in turn enhances clarity of the text, an attribute that makes it possible for users to adhere with the legislation, if they so wish. And it consequently promotes implementation, which is necessary for effectiveness. This is the crucial link between plain language and good legislation. But, if plain language is all about facilitating implementation, does it really matter if successful communication of the legislative message takes place in the first reading?

Moreover, plain language is ... not only about language. Words, syntax, punctuation are very important elements. But so are the structure of the legislative text, its layout on paper and screen, and the architecture of the whole statute book as a means of facilitating awareness of the interconnections between texts. And so plain language begins the kick in during the analysis of the policy and the initial translation into legislation, with the selection and prioritization of the information that readers need to receive. It continues with choices related to structure during the selection and design of the legislative solution, with simplification of the policy, simplification of the legal concepts involved in putting the policy to effect, and initial plain language choices of legislative expression (for example, a decision for direct textual amendments combined by a Keeling schedule, or a repeal and re-enactment when possible). Plain language enters very much into the agenda during composition of the legislative text. And remains in the cards during the text verification, where additional confirmation of appropriate layout and

\footnotetext{
47 This is Mousmouti's effectiveness test: M. Mousmouti, above, n 5, 202.

${ }^{48}$ See R. Posner, 'Cost Benefit Analysis: definition, justification, and comments on conference papers' (2000) 29 The Journal of Legal Studies 1153.

${ }^{49}$ See P. Butt and R. Castle, Modern Legal Drafting (2006, Cambridge University Press, New York).
} 
visually appeal come into play. And so plain language extends from policy to law to drafting.

Recent trends in Europe have developed plain language further. Plain language is a tool promoting uninhibited communication between the text and its users or, to personify the communication, between the drafter and the user. The drafter is a trained lawyer with drafting training and experience. The user of the legislative text can be anything from a senior judge to an illiterate citizen of below average intellectual capacity: the inequality in the understanding of both common terms (whichever these may be) and legal terms renders communication via a single text a hopeless task. What can facilitate communication is the identification of the possible precise users of the specific legislative text: identifying who the users of the text will be allows the text to 'speak' to them in a language that tends to be understood by them. Until now identifying the users was a hypothetical and rather academic exercise. Recent empirical data offered by a revolutionary survey of UK's The National Archives in cooperation with the OPC have provided much needed answers. ${ }^{50}$

Speaking to the users is a noble pursuit but presupposes and understanding of who uses legislation and what level of legal awareness these users have. At the end of the day identifying the people whose choice to act or not makes government policy a success or a failure ${ }^{51}$ is crucial in establishing effective communication with them. But is there one audience of legislation? Can a drafter rely on the common notion of the 'lay person', the 'average man on the street' 52 , the 'user'? The theoretical debate over this point has now been answered by the Good Law Initiative survey: at least three categories of people constitute the audience of legislation, and these are lay persons reading the legislation to make it work for them ${ }^{53}$, sophisticated non -lawyers using the law in the process of their

\footnotetext{
${ }^{50}$ See https://www.gov.uk/good-law.

${ }^{51}$ See D. Berry, 'Audience Analysis in the Legislative Drafting Process' (2000) Loophole, www.opc.gov.au/calc/docs/calc-june/audience.htm.

52 See D. Murphy, 'Plain English-Principles and Practice', Conference on Legislative Drafting, Canberra, Australia, 15 July 1992.

${ }^{53}$ See J. J. E. Gracia, A Theory of Textuality: The Logic and Epistemology (Albany, State University of New York Press, 1995), 159-163, and 164-165; also see G.L. Pi and V. Schmolka, 'A Report on Results of Usability Testing Research on Plain Language Draft Sections of the Employment Insurance Act: A Report to

Department of Justice Canada and Human Resources Development Canada' (unpublished, August 2000); and V. Schmolka, 'Consumer Fireworks Regulations: Usability Testing, TR1995-2e (Department of Justice Canada, unpublished, 1995).
} 
professional activities, and lawyers and judges. In more detail there are three categories of users of legislation:

a. Non-lawyers who need to use legislation for work, such as law enforcers, human resources professionals, or local council officials; the 'Mark Green' of the survey represents about $60 \%$ of users of legislation;

b. Lay persons who seek answers to questions related to their personal or familial situation; 'Heather Cole' represents about $20 \%$ of users of legislation; and

c. Lawyers, judges, and senior law librarians; the 'Jane Booker' persona represents about $20 \%$ of users of legislation. ${ }^{54}$

The significance of the survey for plain language and good legislation cannot be understated. The survey provides, for the first time in UK legislative practice, empirical evidence from a huge sample of the 2,000,000 visitors of www.legislation.gov.uk per month. The survey, whose data relate to users of electronic versions of the free government database of legislation only, destroys the myth that legislation is for legal professionals alone. In fact, legal professionals are very much in the minority of users, although their precise percentage may well be affected by their tendency to use subscription databases rather than the government database, which is not annotated and often not updated. Whatever the exact percentages of each category are, there is significant empirical evidence that in the UK, and most probably in the rest of Europe of which the UK is a representative case study, legislation speaks to three distinct groups of users, whose legal awareness varies from none, to some, too much. But is the legal awareness of the users the only parameter for plain language as a means of effective legislative communication?

Pitching the legislative text to the 'right' level requires an additional consideration. Having realised which are the rough profiles of the audience, the next parameter for plain communication is the topic of the legislative text. Legislative texts are not all aimed at the same readers. Their primary audience varies. For example, the main

\footnotetext{
${ }^{54}$ See A. Bertlin, 'What works best for the reader? A study on drafting and presenting legislation' [2014] The Loophole, https://www.gov.uk/government/uploads/system/uploads/attachment_data/file/326937/Loophole__ 20142 2014-05-09_-What_works best_for the reader.pdf, pp.27-28.
} 
users of rules of evidence are probably judges and lawyers. ${ }^{55}$ So the language and terminology used can be sophisticated: paraphrasing the terms 'intent' or 'mens rea' with a plain language equivalent such as 'meaning to' would lead the primarily legal audience to the legitimate assumption that the legislation means something other than 'intent' and would not easily carry the interpretative case-law of 'intent' on to 'meaning to'. And so rules of evidence can be drafted in specialist language, albeit with a caveat: a primarily legally sophisticated audience cannot serve as a 'carte blanche' for legalese, since nonlawyers may need to, and in any case must, have access to the legislation too. As audiences become more specialized and more educated in technical areas, they expect texts that are targeted to their particular needs. ${ }^{56}$ Moreover, since accessibility of legislation is directly linked to Bingham's rule of law $^{57}$, passing inaccessible legislation under the feeble excuse that its primary audience possesses legal sophistication is not easily acceptable. And so there is an argument for either the continued use of legal terminology or for the provision of a definition of the new plain language equivalent referring to the legal term used until now.

But how 'plain' must legislation be? Even within the 'Heather Cole' persona there is plenty of diversity. There is a given commonality in the lack of legal training, but the sophistication, general and legal, of Heather Coles can range from a fiercely intelligent and generally sophisticated user to a rather naïve, perhaps illiterate, and even intellectually challenged individual. Which of those Heather Coles is the legislation speaking to? It certainly is not the commonly described as 'the average man on the street'. To start with, there are also women on our streets, and they are users of legislation too. And then, why are the above or below averages amongst us excluded from legislative communication? ${ }^{58}$ Since effectiveness is the goal of legislative texts, should legislation not speak to each and every user who falls within the subjects of the policy solution expressed by this specific legislative text? This includes the above average, the average, and the below average people.

\footnotetext{
${ }^{55}$ See B. A. Garner 'Guidelines for drafting and editing court rules' [1997] Federal Rules Decisions 169, 187.

${ }^{56}$ See K. A. Schriver, 'Plain Language through Protocol-Aided Revision' in E. R. Steinberg (ed.), Plain Language: Principles and Practice (Detroit, Wayne State University Press, 1991), 148, 152.

${ }^{57}$ See Lord Simon of Glaisdale, 'The Renton Report-Ten Years On’ (1985) Statute Law Review 133.

${ }^{58}$ See J. Kimble, 'Answering the Critics of Plain Language' (1994-1995) 5 The Scribes Journal of Legal Writing 51, 59.
} 
This is a rather revolutionary innovation. Identifying the users of legislation has led to not one but two earthquakes in legislative studies: yes, the law does not speak to lawyers alone; but the law does not speak to the traditional plain language 'average man'. The significance of this innovation cannot be side-lined. Identifying the users has provided irrefutable empirical evidence on who uses legislation, and for what purpose. If applied in practice, this new knowledge will change the way in which legislation is drafted in Europe and beyond. First, legislative language can no longer be gauged at legal and regulatory professionals. Although great advances have already taken place, legislation now tends to be pitched to 'Mark Green': further simplification to the benefit of 'Heather Cole' needs to take place with immediate effect.

Dealing with language is not enough, especially when the modern holistic concept of plain language is taken into account. Scientists outside the discipline of law can and must contribute to the introduction of novel mechanisms for the production of plain and effective legislation.

Having established the concept of effectiveness as synonymous to good legislation, and the new holistic mandate of plain language in legislation, and armed with the new empirical data offered by TNA and OPC, let us discuss further possibilities. I have identified three blue sky mechanisms for better law. They respond to widely accepted faiblesses in European legislation stemming from the newly identified need for legislation to speak to three diverse user groups with a single text: the layered structure promotes a three tier structure for legislative texts each addressed to each of the three user groups; the typography inspired presentation and layout responds to the need to bring to light the main regulatory messages in legislation; and the interactive electronic statute book highlights the interconnectivity between legislative texts within the statute book as a whole.

\subsubsection{The layered approach to structure}

Currently legislative texts are structured in application to Lord Thring's Five Rules of Drafting $^{59}$ that offers precedence to provisions declaring the law versus provisions

\footnotetext{
${ }^{59}$ See Lord Thring, Practical Legislation, The Composition and Language of Acts of Parliament and Business
} 
relating to the administration of the law; to simpler versus the more complex proposition; and to principal versus subordinate provisions. Exceptional, temporary, and provisions relating to the repeal of Acts, and procedure and matters of detail should be set apart.

The application of Thring's rules have led to a traditional legislative structure of preliminary, miscellaneous, and final provisions. There is much scope for blue sky innovation by use of the layered approach ${ }^{60}$. The rationale behind the modern approach lies with the logical sequence of provisions within the text, which reflects logic, and philosophical and linguistic approaches to language and thought. This basis has now been overcome by the crucial evidence on the three user groups for legislation. Heather Cole, Mark Greene, and Jane Booker are diverse users that require diverse pitches of the legislative text. Speaking to all three of them at the same time is a rather complex, for some impossible, task. Introducing three versions of the same legislative text is a possibility but it is a recipe for disaster on such a diverse range of grounds, moral, ethical, constitutional, practical: rule of law, issues of interpretation between versions, identifying which version corresponds to each user, using that version as opposed to the one selected by the user, who subjects each user to their corresponding persona, ethical and moral consequences of the application of a diverse version for each user. And the parallel existence of three different texts could be counter-productive: users currently choose to use the complex but official legislative text over any of the many interpretation aids offered by government. If the plethora of attractive user friendly manuals and policy documents are shunned in favour of legislative texts, what makes it probable that users will go to the simple Heather Cole text as opposed to the legal Jane Booker one that reflects users' perception of legislation? And so remaining with a single text is really the only option. But this is exactly what has imprisoned legislative drafters in the struggle for simplicity within legislative texts.

It is now possible to see that each user group has its individual requirements for legislative information that are distinct from those of the other user groups. Identifying the needs for legislative information for each user group at a provision, rather than text, level would allow drafters to imitate oral communication, and pitch the legislative text to

Documents (London, 1902), 38; also see V.C.R.A.C. Crabbe, Legislative Drafting (Oxford, Cavendish Publishing, 1998), 148-150.

${ }^{60}$ The term, and to a certain extent, the concept is attributed to John Witing, Tax Director at the Tax Simplification Office. I am very grateful to John for his inspiration and the generosity with which he has shared it with me. 
specific abilities and requirements. Drafters of legislative texts can now begin to think what regulatory or legal message is relevant to each group, and structure the text accordingly.

The layered approach promotes the division of legislation into three parts, corresponding to each of the three profiles of legislative users. Part 1 can speak to lay persons: the content is limited to the main regulatory messages, thus conveying the essence of law reform attempted by the legislation, focusing gravely on the information that lay persons need in order to become aware of a new regulation, to comply with new obligations, or to enjoy new rights. Part 2 can speak to non-legally trained professionals who use the legislation in the course of their employment. Here one can see scope for further detail in the regulatory messages introduced, and for language that is balanced [technical, yet approachable to the professionals in question]. Part 3 of the legislation can then deal with issues of legislative interpretation, issues of procedure, and issues of application, in a language that is complex but not quite legalese, as there is nothing to prevent all groups from reading all parts.

The layered approach is revolutionary, as it shifts the criterion for legislative structure from the content and nature of provisions to the profile of the users. It switches on a user-centred structure, thus promoting both a link between policy and its effecting legislative text but also enhancing and personalising the channel of communication between drafters and users. And it applies and reflects the modern doctrine of contextualism in language and philosophy. But it cannot be viewed as a complete departure from tradition, as it continues to apply Lord Thring's five rules. By requiring that Part 1 includes the primary regulatory message, it promotes Lord Thring's rules that give precedence to the simpler proposition. And by structuring legislation into three parts, the layered approach complies with the other Thing rules that require division of provisions declaring the law [in Part 1 or 2] with provisions administrating the law [in Part 2 or 3 accordingly]; that principal provisions should be separated from subordinate [in Parts 1 and 2]; that exceptional, temporary, and provisions relating to the repeal of Acts should be separated from the other enactments, and placed by themselves under separate headings [in Part 3]; and that procedure and matters of detail should be set apart by themselves [either in Part 3 of the layered approach, or in a Schedule].

The layered approach seems to be one of the promising initiatives in the field of legislation. But there are three points that need to be clarified. First, the layered approach 
may, but will not necessarily, lead to a partial, fragmented, or incomplete legislative communication to Heather Cole. There is no doubt that an erroneous application of the approach could result to that. But the placement of the main messages in Part 1 per se must be seen as an added bonus to lay users compared with the current state of affairs: in the layered approach the now frequently elusive main regulatory message will be easily identified, will be brought forward in a pronounced place at the beginning of the legislative text, and will be expressed in a language that is accessible to lay users. Compared to the current state of affairs, where the main message is communicated somewhere within the legislative text and is expressed in the layered approach's Part 2 or 3 language, this is certainly an improvement. And of course, there is nothing preventing Heather Cole from reading the rest of the text: in fact, an inviting Part 1 can only encourage Heather Cole to keep reading, whilst offering her a clear context within which her understanding of complex and detailed messages can only be enhanced.

Second, although Part 1 carrying the main regulatory message is distinctly different from Parts 2 and 3, it may be unclear what really distinguishes between Part 2 data and Part 3 data: both Mark Green and Jane Booker are able to handle complexity and technicality of legislative data. However, they do not both require the same data, as demonstrated by their motives when using www.legislation.gov.uk: Mark Green is interested in answers that allow him to perform his professional but non-legal duties, whereas Jane Booker seeks legal information. As a result, what Mark Green needs is a clear understanding of substantive and procedural requirements imposed by the legislation, whereas Jane Booker seeks deeper statutory interpretation often coupled with a holistic view of the statute book. As a result, Part 2 of the layered approach involves answers to questions such as who must do what by when, and what happens if they don't. Part 3 will delve deeper into intricate distinctions and possible exceptions that relate to statutory interpretation and interconnections between legislative texts within the statute book. There are two caveats here. One, Mark Green must still read the text as a whole. And Part 3 cannot be viewed as a mere shell of definitions, repeals, and consequential amendments: this would deprive the readers from at least part of the benefits of the layered approach.

Third, it would be inappropriate to consider that the simplification serviced by the layered approach would result to an abolition of the need for explanatory materials for legislation. In fact, as the layered approach results in an inherent fragmentation of data, it 
renders the use of explanatory materials and notes reinstating the fluidity of information and the cross-fertilisation between parts an ever so crucial requirement.

Ultimately, the proof of the layered approach is in its application. User testing can prove whether it works, which user group for, and how it can be amended or fine-tuned to serve users better.

\subsubsection{Legislative image: presentation, layout, pictures}

Looking now in the image of the legislative text, namely at the picture that the user receives when looking at the text, it is necessary to distinguish between paper and electronic. It is noteworthy that in New Zealand legislation is only published electronically: paper publication ceased last year. In Europe I am not aware of government intent to abolish paper publication but there certainly is a move to a more user friendly electronic version of legislation.

Plain language has always advocated the need to rethink the layout of legislative texts. ${ }^{61}$ The single font, the lack of adequate contrast between paper and text, the unique format are elements of the current legislative image that prevent the user from identifying the important aspects of the regulatory message thus reducing readability of legislative texts. Legislative texts attempt to convey a 'legislative story' to the user, thus allowing them to identify and then understand the underlying policy, the legislative choices made, and the rationale behind the text. This offers them the ability to read and interpret the text in context, thus making accessibility easier and more secure.

However, there is plenty of scope for further progress. Layout is now at the forefront of practitioners' agenda. And quite rightly so. It has been overlooked and there is great scope for change. However, layout alone cannot respond to a complex text, to a complex regulatory message, or indeed to a complex policy. It will contribute to simplification but with the aid of additional visual tools.

One of those tools that have been ignored by even the most visionary of legislative academics and practitioners is the use of image in legislation. Images have been used in legislation that introduces national flags, traffic signs, or planning regulations. But the

\footnotetext{
${ }^{61}$ See Office of Scottish Parliamentary Counsel, 'Plain language and legislation', February 2006, http://www.gov.scot/resource/doc/93488/0022476.pdf.
} 
relationship between picture and legislation has not been explored fully. The visual arts could play a significant role here: there is nothing more direct, relevant to a wide range of users, and time resistant than Cain swinging his club above the prostrate Abel in Titian's painting in Santa Maria della Salute in Venice. The visual representations of themes relating to wrongdoing are so emotionally charged and the characters shown in such magnification that, combined with beauty and other aesthetic values, picture has had tremendous impact on the viewer.

Perhaps the inclusion of images in legislation can enhance the quality of communication. An example could be drawn from criminal provisions. The picture accompanying the legislation in the form of a Schedule may show:

- what behaviour is to be condemned (show the action; and specify if the person knows that this is bad, suspects that this is bad, or is ignorant of the badness of the behaviour); and

- that this is an offence (for example show a stop sign or show societal disapproval); and

- that it carries a sanction (for example show the penalty and its adverse effect).

The use of typographical and visual aids in legislation can enhance readability ${ }^{62}$ immensely. They can address textual limitations and can take the user further by banishing the barriers or written textual communication. User testing is the only way to assess if and how useful they are. But academic research, indeed inter-disciplinary academic research, is the only forum for analysis at a theoretical level first, and then in application to actual legislation.

\subsubsection{The statute book or the body of legislation as a whole: quantity and beyond}

Reforming the structure and layout of individual legislative texts may bear little fruit without changes in the statute book as a whole. Addressing the issue of legislative volume

\footnotetext{
${ }^{62}$ See G. Jones, P. Rice, J. Sherwood, J. Whiting 'Developing a Tax Complexity Index for the UK', https://www.gov.uk/government/uploads/system/uploads/attachment_data/file/285944/OTS_Developing a_Tax_Complexity_Index_for_the_UK.pdf.
} 
that enhances complexity ${ }^{63}$ has been at the forefront of the agendas of the last two governments as the epicentre of regulatory quality. The volume of legislation came under review in the UK in 2003. The Better Regulation Task Force's 'Principles of Good Regulation' $^{64}$ linked better regulation with less legislation, and offered a number of regulatory alternatives: do nothing; advertising campaigns and education; using the market; financial incentives; self-regulation and voluntary codes of practice; and prescriptive regulation. In 'The Coalition: our programme for government ${ }^{65}$ the previous government undertook to cut red tape ${ }^{66}$ by introducing a 'one-in, one-out' rule whereby no new regulation is brought in without other regulation being cut by a greater amount; ${ }^{67}$ and to impose sunset clauses on regulations; and to give the public the opportunity to challenge the worst regulations. Such was the importance attributed to legislative volume that the Prime Minister in his letter of 6 April 2011 to all Cabinet Ministers declared:

'I want us to be the first Government in modern history to leave office having reduced the overall burden of regulation, rather than increasing it.'

In order to achieve this aim, the UK government went one step further and introduced a one-in two-out approach. It undertook to use regulation for the achievement of its policy objectives only where non-regulatory approaches cannot lead to satisfactory outcomes; cost benefits analysis demonstrates a clear margin of superiority of regulation to alternative, self-regulatory, or non-regulatory approaches; or the regulation and the enforcement framework can be implemented in a fashion which is demonstrably proportionate; accountable; consistent; transparent and targeted. ${ }^{68}$ The number of Acts passed in 2012 was only 20 with a total number of pages of $1,886^{69}$ : this was a new low after the peak of the late 1990s and early 2000s. But, whilst the number of Acts has

\footnotetext{
${ }^{63}$ See Office of Parliamentary Counsel 'When Laws Become Too Complex: A review into the causes of complex legislation, March 2013,

https://www.gov.uk/government/uploads/system/uploads/attachment_data/file/187015/GoodLaw_report 8April_AP.pdf, 6-7.

${ }^{64} \mathrm{See}$

http://webarchive.nationalarchives.gov.uk/20100407162704/http:/archive.cabinetoffice.gov.uk/brc/upload /assets/www.brc.gov.uk/principlesleaflet.pdf.

${ }^{65}$ See 'The Coalition: our programme for government', https://www.gov.uk/government/uploads/system/uploads/attachment_data/file/78977/coalition_programm e for_government.pdf.

${ }^{66}$ For further information on the Red Tape Challenge, see http://www.redtapechallenge.cabinetoffice.gov.uk/home/index.

${ }^{67} \mathrm{See}$ http://www.bis.gov.uk/assets/biscore/better-regulation/docs/o/11-671-one-in-one-out-methodology.

${ }^{68}$ See Department for Business, Innovation and Skills, 'Better Regulation Framework Manual', July

2013, https://www.gov.uk/government/uploads/system/uploads/attachment_data/file/211981/bis-13-1038better-regulation-framework-manual-guidance-for-officials.pdf, 4.

${ }^{69}$ See HoL Library Note 2013/008, Volume of Legislation, 4.
} 
decreased since the 1980s, the mean average number of pages per Act has increased significantly, from 37 and 47 pages during the 1980s and 1990s respectively, to 85 in the past decade; if one compares these numbers with the 1950s when the average was 16, a trend of fewer but longer Acts becomes evident. ${ }^{70}$ One could contribute this increase to plain language drafting and to the increasing amounts of white space and bigger margins leading to $20 \%$ fewer words on a page. ${ }^{71}$ However, there is a crucial contributing factor: over the last 30-40 years the number of Statutory Instruments has steadily increased. ${ }^{72}$ And so the volume of legislation, including primary and delegated, seems to be fighting its ground in practice. ${ }^{73}$ Nonetheless, a recent OECD Review pronounces the regulatory reforms in the UK as impressive. ${ }^{74}$ Points of excellence include the effective balance between policy breadth and the stock and the flow of regulation; and the extensive application of EU's Better Regulation initiatives in the $\mathrm{UK}^{75}$.

But of course innovations to the statute book do not end with legislative volume. Blue sky proposals, which in this case may be put to effect much quicker than one might expect.

\subsubsection{The theoretical umbrella: phronetic legislative drafting}

So legislative studies and legislative practice is rapidly progressing to its age of maturity via a number of innovations. These are not only found in Europe. In fact, legislative innovation is happening all over the world. This rampage of fresh and innovative thinking is not haphazard: it reflects, and is evidence of, academic innovation in legislative studies theory. Until recently legislative drafting was viewed as a mere skill, normally and mostly, served by government lawyers. But things have changed. Legislation became the focus of regulation replacing the common law. There are a number of possible causes for this phenomenon: the Europeanisation of law offered common law systems the

\footnotetext{
${ }^{70}$ See HoL Library Note, Volume of Legislation, LLN 2011/028, September 2011.

${ }^{71}$ See R. Heaton, House of Commons Political and Constitutional Reform Committee 'Ensuring standards in the quality of legislation' First Report of Session 2013-14, HC 85 Incorporating HC 74-i to vii, Session 2012-13, 20 May 2013, Question 64.

${ }^{72}$ See R. Cracknell and R. Clements 'Acts and Statutory Instruments: the volume of UK legislation 1950 to 2012' HoC Standard Note SN/SG/2911, 15 November 2012, 2.

${ }^{73}$ And not just in the UK: see R. Pagano Introduzione alla legistica - L'arte di preparare le leggi (Milano, Giuffre, 1999) 6.

${ }^{74}$ See http://www.oecd.org/dataoecd/61/60/44912018.pdf.

${ }^{75}$ For a listing of such policies and their implementation in the UK, see http://www.bis.gov.uk/policies/bre/improving-eu-regulation/guiding-principles-eu-legislation.
} 
opportunity to appreciate more the feared statutory law; legal globalisation led to an emphasis on international statutory law (treaties etc.) that required national implementation via national statutory law; and finally the realisation that regulation was passed for the purposes of achieving measurable results led to the inevitable [and not always fortunate] use of statutory law as a method of regulation. Whatever the reason, it invited a detailed study of statutory law from its conceptualisation to its implementation. And paved the way for a new theory for legislative drafting ${ }^{76}$.

The traditional view, mostly within the common law world, is that drafting is a pure form of $\operatorname{art}^{77}$ or a quasi-craft ${ }^{78}$ : if drafting is an art or a craft, then creativity and innovation lies at the core of the task; rules and conventions bear relative value. In the civil law world drafting is viewed as science ${ }^{79}$ or technique ${ }^{80}$ : it carries formal rules and conventions whose inherent nomoteleia manages to produce predictable results. But, if drafting is viewed as a sub-discipline of law, then there is a third option: law is not part of the arts, nor is it part of the sciences ${ }^{81}$ in the positivist sense. ${ }^{82}$ In science rules apply with universality and infallibility: gravity will always make an object fall down. Law is different: 'All law is universal but about some things it is not possible to make a universal statement which will be correct... the error is not in the law nor in the legislator but in the nature of the thing ${ }^{83}$ But rejecting the view that drafting is a science does not necessarily confirm that drafting is an art. Art tends to lack any sense of rules. In the pursuit of aesthetic pleasure, art uses whatever tools are available. Art is anarchic. Drafting is not. Of course its rules are not rigid, but they are present. There may be exceptions to all rules of drafting, but this does not mean that there are no rules. And these rules carry with them a degree of relevant predictability, since the latter is one of the six elements of theory. ${ }^{84}$

\footnotetext{
${ }^{76}$ See H. Xanthaki, 'Duncan Berry: A true visionary of training in legislative drafting' [2011] The Loophole, pp.18-26.

77 See B. G. Scharffs, 'Law as Craft' (2001) 45 Vanderbilt Law Review, 2339.

78 See C. Nutting, 'Legislative Drafting: A Review' (1955) 41 American Bar Association Journal, 76.

79 See contra Editorial Review, 22 [1903] Can. L. Times, 437.

80 See contra J.-C. Piris, 'The legal orders of the European Union and of the Member States: peculiarities and influences in drafting' [2006] EJRL, 1.

${ }^{81}$ For an analysis of the contra argument on law as a science, see M. Speziale, 'Langdell's Concept of Law as Science: The Beginning of Anti-Formalism in American Legal Theory' 5 [1980] Vt. L. Rev.1. ${ }^{82}$ See R. R. Formoy, 'Special Drafting' 21 [1938] Bell Yard: J.L. Soc'y Sch. L. 3; but see contra C. Langdell, 'Harvard Celebration Speeches', 3 [1887] LAW Q. Rev. 123-124.

${ }^{83}$ See Aristotle, E.N., 5.10.1137b13-24.

${ }^{84}$ See B. Flyvbjerg, Making Social Science Matter: Why social inquiry fails and how it can succeed again', (2001, Cambridge University Press, Cambridge) 39
} 
For Aristotle ${ }^{85}$ all human intellectuality can be classified as ${ }^{86}$ science as episteme; art as techne; or phronesis ${ }^{87}$ as the praxis of subjective decision making on factual circumstances or the practical wisdom of the subjective classification of factual circumstances to principals and wisdom as episteme. ${ }^{88}$ Law and drafting seem to be classical examples of phronesis, as they are liberal disciplines with loose but prevalent rules and conventions whose correct application comes through knowledge and experience. Drafting as phronesis is 'akin to practical wisdom that comes from an intimate familiarity with contingencies and uncertainties of various forms of social practice embedded in complex social settings'. ${ }^{89}$ The art of drafting lies with the subjective use and application of its science, with the conscious subjective Aristotelian application and implementation of its universal theoretical principles to the concrete circumstances of the problem. ${ }^{90}$ Phronesis supports the selection of solutions made on the basis of informed yet subjective application of principles on set circumstances. ${ }^{91}$ Phronesis is "practical wisdom that responds to nuance and a sense of the concrete, outstripping abstract or general theories of what is right. In this way, practical wisdom relies on a kind of immediate insight, rather than more formal inferential processes'. ${ }^{92}$ And so drafting legislation simply involves the choice of the appropriate rule or convention that delivers the desired results within the unique circumstances of the specific problem at any given time. And, under this functional prism, successful drafting is the production of a good law, namely an effective law that contributes to regulatory efficacy. ${ }^{93}$ There is nothing technical with qualitative functionality here: what counts is the ability of the law to achieve the reforms requested by the policy officers. In view of the myriad of parameters that are unique in each dossier, there are no precise elements of quality at this level.

\footnotetext{
${ }^{85}$ See Aristotle, Nichomachean Ethics, bk VI, chs. 5-11 (D. Ross trans. 1980).

${ }^{86}$ See M. Griffiths and G. Macleod, 'Personal narratives and policy: never the twain?' [2008] 42 JPE $121,126$.

${ }^{87}$ See Aristotle, note 106.

${ }^{88}$ See S.-U. von Kirchmann, Die Werlosigkeit der Jursprudenz als Wissenschaft (1848, Verlage von Julius Springer, Berlin).

${ }^{89}$ See B. Caterino and S. F, Schram, 'Introduction' in S. F. Schram and B. Caterino, Making political science matter: Debating knowledge, research, and method (2006, New York University Press, New York) 8 .

90 See W. Eskridge Jr., 'Gadamer/Statutory interpretation’ [1990] 90 ColumLRev 635.

${ }^{91}$ See E. Engle, 'Aristotle, Law and Justice: the tragic hero' [2008] 35 NKyLRev 4.

${ }^{92}$ See C. Rideout, 'Storytelling, narrative rationality, and legal persuasion' [2008] 14 Legal Writing: J. Legal Writing Inst. 75.

${ }^{93}$ See H. Xanthaki, 'Drafting manuals and quality in legislation: positive contribution towards certainty in the law or impediment to the necessity for dynamism of rules?' [2010] 4 Legisprudence 111.
} 
This qualitative definition of quality in legislation respects and embraces the subjectivity and flexibility of phronetic legislative drafting. ${ }^{94}$ Phronetic legislative drafting does not ignore the elements of art and science identified within the discipline; it focuses on the subjectivity of prioritisation in the selection of the most appropriate virtue to be applied by the drafter in cases of clash between equal virtues. But subjectivity is not anarchic: it is qualified by means of recognising effectiveness as the sole overriding criterion for that choice. In phronetic legislative drafting one must be able to identify basic principles which, as a rule, can render a law good. The pyramid in the beginning of this paper presents such principles: when applied, at least in the majority of cases, they lead to good law. Yet the ultimate criterion of good law is its effectiveness, at least under the prism of phronetic legislative theory, a theory that has innovated legislative study and legislative practice in Europe and beyond.

\subsection{Conclusions}

Perhaps the biggest innovation in legislation and legislative studies is the realisation that the partnership between legislative professionals and legislative academics provides a dynamic combination of appropriate research methodology and internally available government held empirical legislative data: when the two gel, they can produce academically valid and practically useable know-how whose empirical impact can change our whole perception of legislation and the statute book. Challenging as it is, the new research agenda offers academics the comfort of a sound theoretical framework within which any cooperation is to flourish: phronetic legislative drafting views the study of legislation as a new sub-discipline of legal science, thus allowing it to benefit from the wealth of theoretical and empirical analyses in substantive fields of law that can serve as persuasive case studies for the further development of both the substantive law and the legislative fields of study. Blue skies await ahead, and Europe has a leading role to play both via its academics and via its practitioners. Perhaps this book constitutes the first step to the right direction.

\footnotetext{
${ }^{94}$ See H. Xanthaki, 'Quality of legislation: an achievable universal concept or a utopian pursuit?' in Marta Travares Almeida (ed.), Quality of Legislation (2011, Nomos, Baden-Baden), pp.75-85.
} 